\title{
BMJ Open aDolescent and prEconception health peRspectiVe of Adult Non- communicable diseases (DERVAN): protocol for rural prospective adolescent girls cohort study in Ratnagiri district of Konkan region of India (DERVAN-1)
}

To cite: Patil S, Patil N, Joglekar C, et al. aDolescent and prEconception health peRspectiVe of Adult Noncommunicable diseases (DERVAN): protocol for rural prospective adolescent girls cohort study in Ratnagiri district of Konkan region of India (DERVAN-1). BMJ Open 2020;10:e035926. doi:10.1136/ bmjopen-2019-035926

- Prepublication history for this paper is available online. To view these files, please visit the journal online (http://dx.doi org/10.1136/bmjopen-2019035926).

Received 22 November 2019 Revised 19 July 2020 Accepted 06 August 2020

Check for updates

(C) Author(s) (or their employer(s)) 2020. Re-use permitted under CC BY-NC. No commercial re-use. See rights and permissions. Published by BMJ.

For numbered affiliations see end of article.

Correspondence to

Dr Suvarna Patil;

dr.suvarnanpati@gmail.com

Suvarna Patil (D) , ${ }^{1}$ Netaji Patil, ${ }^{2}$ Charudatta Joglekar, ${ }^{3}$ Arvind Yadav, ${ }^{4}$ Anup Nilawar, ${ }^{4}$ Ulka Banavali, ${ }^{3}$ Rohit Bhat, ${ }^{3}$ Vijay Dombale, ${ }^{5}$ Bhushan Warpe, ${ }^{5}$ Rachana Mohite, ${ }^{3}$ Kiran Joshi ${ }^{6}$

\section{ABSTRACT}

Introduction Precise impact of nutritional insufficiencies in adolescence as a risk factor for non-communicable diseases (NCD) in later life as adults remains largely unknown.

We are conducting research into the effects of nutrition on adolescent girls of Ratnagiri district by a prospective cohort study (aDolescent and prEconception health peRspectiVe of Adult Non-communicable diseases cohort). Our study focuses on the physical health, nutritional parameters and cognitive profiles of adolescent girls, during the prenatal and postnatal period and we aim to follow this cohort and their offspring for 20 years. Methods and analysis Cohort recruitment began in June 2019. Our aim is to recruit more than 1500 adolescent girls, age 16-18 years, over a period of 3 years. The recruit's cognition, diet and physical activity will be recorded. The following investigations will be performed: body composition by anthropometry and bioimpedence, and blood pressure, fasting blood sample to measure glucose, insulin, lipids, micronutrients and hormones, abdominal ultrasonography to measure liver, pancreas and kidneys. A biorepository has been created for long-term storage of blood, urine and saliva samples for future analysis. By this longitudinal study, we aim to identify the effects of malnutrition on the behavioural and biological measures in adolescent subjects and evaluate if these are associated with the onset of NCDs in adulthood.

Ethics and dissemination Institutional Ethic Committee (IEC) of BKL Walawalkar Rural Medical College and Hospital has granted the permission to carry out the study. IEC is registered with Government of India. Its registration code is $\mathrm{EC} / 755 / \mathrm{INST} / \mathrm{MH} / 2015 / \mathrm{RR}-18$. It is not a clinical trial but as required we have also registered the study on Clinical Trial Registry of India (CTRI). The registration code is CTRI/2019/04/018453.

Appropriate written informed consent and assent are obtained from the parents and the adolescent girls, respectively. We plan to publish our results in peerreviewed journals.
Strengths and limitations of this study

- This is the first adolescent cohort from Konkan region where no prior detailed epidemiological data is available apart from few government surveys.

- This study will enable us to understand the health profile of the region's adolescent girls and assess their health priorities. Long-term follow-up will provide longitudinal assessment of the risk factors for the development of non-communicable diseases (NCDs) in their adulthood and in their future offsprings.

- Since adolescent boys have been excluded from the study, we will not be able to assess the impact of paternal nutrition on the occurrence of NCDs in the future generations.

- Poor participation by fathers of adolescent girls will limit assessment of the parental contribution to outcomes in the next generation.

\section{INTRODUCTION}

The Developmental Origins of Health and Disease (DOHAD) concept $^{1}$ postulates that exposure to environmental factors such as under nutrition, stress and infection in early life can influence the long-term risk of noncommunicable diseases (NCD). India is witnessing an escalating incidence of NCD. ${ }^{2}$ Indians are particularly prone to diabetes and India is expected to have more than 70 million people with diabetes by $2030 .{ }^{34}$ Indians develop diabetes at a younger age and at a lower body mass index as compared with the Europeans. ${ }^{5}$ The intrauterine period is critical in child development and therefore for the risk of developing NCDs in later adulthood as well. There is increasing evidence of 
the impact of maternal preconceptional stress including poor nutrition on the fetal neurodevelopment. ${ }^{6}$

Adolescence is a period of rapid growth creating increased demand for energy and nutrition. It has been postulated that nutritional deficiency during adolescence can have a negative impact on the future health of the individual. This is particularly important in girls as malnutrition will also affect their offspring. ${ }^{78}$ Negative effects of adolescent malnutrition can persist throughout the reproductive life. Adolescence can be an opportunity to correct nutritional deficiencies and thus possibly reduce the the risks of development of NCDs in later adulthood. However, the efficacy of adequate nutrition in adolescents to reduce the risks for future adult onset of NCD's remains largely unknown. Recent research has shown that maternal nutrition, through effects on fetal development, influences metabolism throughout life. Both maternal undernutrition and obesity adversely 'programme' the fetus, leading to an increased risk of adult NCDs. ${ }^{9-12}$ Therefore, the health of an adolescent girl is important for the health of her future baby. In rural India, adolescent girls face serious health problems due to socioeconomic deprivation, poor environmental conditions, inadequate nutrition, gender discrimination and anaemia. ${ }^{13} 14$ Anaemia not only affects physical health, but also affects cognitive function and scholastic performance. ${ }^{15}$ Adolescent girls are particularly vulnerable to developing anaemia because of rapid growth, weight gain, blood volume expansion and onset of menstruation. Anaemic adolescent girls subsequently have low birth weight (LBW) babies. In India, the rate of LBW, prematurity, and neonatal and infant mortality are high among children born to undernourished mothers. ${ }^{16} 17^{\circ}$

Micronutrients such as vitamins and minerals play an important role in the promotion of health and prevention of disease in adolescents. ${ }^{18}$ Micronutrient deficiency unlike energy-protein undernourishment is not clinically apparent. It is commonly called as 'hidden hunger' and largely goes unnoticed by the general public, decisionmakers and even by the affected individuals. ${ }^{19}$ Micronutrient deficiency is mainly caused by the lack of a balanced diet. Ensuring adequate nutrition for adolescents provides an opportunity for healthy transition from childhood to adulthood thus breaking the cycle of intergenerational malnutrition. Study conducted in the city of Udaipur in the state of Rajasthan from India, ${ }^{20}$ and an eight state report from India, ${ }^{21}$ showed that most of the adolescent girls failed to meet the dietary recommendations in almost all of the food groups. In addition, most of these girls failed to have adequate consumption of important micronutrient rich foods. Adolescent girls often skipped meals on regular basis and followed a two meal pattern. These findings confirm that adolescent girls in India are at a high risk of nutritional deficiency.

Interventions aimed at preventing micronutrient malnutrition typically have focused on pregnant women and young children. However, there is increasing evidence that micronutrient malnutrition is also prevalent in

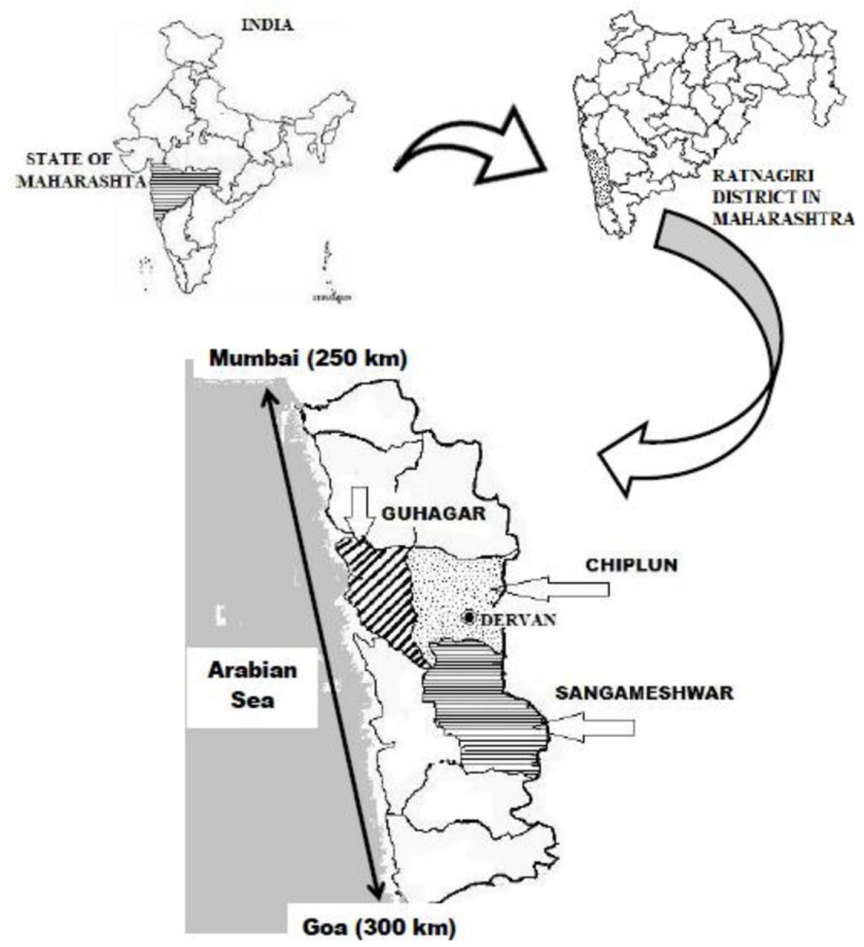

Figure 1 Geographical location of Dervan.

adolescent girls. ${ }^{22}$ Appropriate and targeted interventions are needed to monitor and evaluate progress in our efforts to prevent and control these deficiencies. Many strategies to improve nutrition and health behaviours before conception have been suggested. ${ }^{23}$ Over the last two decades, India has witnessed a rapid socioeconomic transition ${ }^{24}$ and has seen a dramatic rise in the prevalence of obesity, diabetes and coronary heart disease. At the same time, India also has a high prevalence of maternal under nutrition, LBW babies and childhood malnutrition as well. ${ }^{25}$

\section{Background}

Bhaktashreshtha Kamalakarpant Laxman(BKL) Walawalkar Hospital is located in a remote, rural village of Dervan (figure 1) located in the western Indian state of Maharashtra, situated $250 \mathrm{~km}$ south of Mumbai and 300 $\mathrm{km}$ north of Goa. The area falls in the coastal region of "Konkan". It has established a well-developed network with all anganwadi (children day care centres) and zilla parishad (local government) schools for various community programmes. The hospital has been running adolescent health programmes for many years and has collected extensive data on the health of adolescent girls in Ratnagiri district. Our data suggest that $40 \%$ of adolescent girls were anaemic and $75 \%$ were suffering from menstrual irregularity. ${ }^{26}$ Another study on 1290 school going rural adolescent girls reported anaemia prevalence of $47 \%$. About 78\% had poor verbal expression and sleep disturbances. ${ }^{27} \mathrm{~A}$ small cross-sectional study on 80 adolescent girls showed association between micronutrient deficiencies and psychological impairment. ${ }^{28}$ 
India has been on the forefront of $\mathrm{DOHaD}$ research, and though all the research points toward nutritional deficiencies at various stages of life cycle, actual findings of various studies vary considerably. ${ }^{25}$ Given these variations and the findings of our cross-sectional studies ${ }^{26-28}$ over the last two decades, we concluded that further systematic research is needed. Therefore, we have designed a prospective cohort study of adolescent girls of the Ratnagiri district. Our study will extend the DOHaD perspective by focusing on the physical health, nutrition and cognitive profiles of girls in adolescence as well as in the prenatal and antenatal period.

\section{Aims}

Our study will test the following hypothesis: Poor physical growth and poor nutrition in adolescent girls increases the risk of NCDs, in particular the risk of diabetes in their adulthood and in their offsprings. Our objective is to set up a cohort of adolescent girls. It has been named aDolescent and prEconception health peRspectiVe of Adult Non-communicable diseases (DERVAN) COHORT. The study will recruit adolescent girls of Ratnagiri district and longitudinally follow them and their offspring.

\section{OBJECTIVES}

\section{At recruitment}

1. To assess the body composition, blood pressure, nutrition, physical activity and cognitive function in adolescent girls.

2. Measure the level of metabolites and micronutrients in the blood samples of adolescent girls.

3. To assess the body composition of parents and record the family history of NCDs.

4. To establish a bio repository for the preservation of serum, saliva, and urine samples of adolescent girls and their parents.

5. Conduct sessions about awareness and health education for the adolescents as well as their parents.

\section{Post recruitment}

1. Continue to follow up the recruited girls annually until their marriage for body composition, blood pressure, glucose tolerance and complete blood count.

2. After marriage assess the body composition, blood pressure, nutrition, physical activity and cognitive function and measure glucose tolerance, complete blood count, metabolites and micronutrients in the blood samples.

3. Follow the married women systematically in pregnancy by assessing the body composition, blood pressure, nutrition, physical activity, cognitive function, glucose tolerance, complete blood count and metabolites and micronutrients in the blood samples.

4. Collect cord blood sample at delivery, perform neonatal body composition using anthropometry.

5. Continue to follow the mothers and neonates postnatally for 20 years.

\section{STUDY DESIGN AND METHODOLOGY}

\section{Sample size}

Estimating the required Sample size based on our hypothesis was challenging due to the lack of similar studies in rural India. We were able to identify only two cohort studies; one was a rural cohort, the Pune Maternal Nutrition Study (PMNS), and the other was an urban cohort, the Parthenon study from the city of Mysore. ${ }^{25}$ Both of these studies have a sample size in the range of 600-800 individuals. However, these studies have not yet published data correlating the impact of adolescent nutrition with the onset of NCD or diabetes in their offspring. Data on the prevalence of many factors are limited. Hence, we decided to calculate the sample size for our rural region, based on an Indian Council of Medical Research-INdia DIABetes (ICMR-INDIAB) study ${ }^{29}$ which reported type 2 diabetes mellitus prevalence of $6.5 \%$ in rural Maharashtra. We used sample size estimation technique laid out by Lwanga et al..$^{30}$ Allowing a relative precision of $20 \%$, a nonresponse/attrition rate of $10 \%$ and $\alpha$ error of $5 \%$ we arrived at a sample size of 1520 . It might also be noted that if the community engagement succeeds in having a positive health promotion effect, then risk is likely to be reduced in the sample.

\section{Sampling}

We are recruiting study subjects from the villages of three tehsils (administrative areas within the larger district created by the government): Chiplun, Guhagar and Sangameshwar of the Ratnagiri district located in the southwestern Indian state of Maharashtra (figure 1).

A three-stage design (Tehsil-Village-Household) was used. Three level stratification was done based on the geographical distribution and the population size of the villages to provide a sample of adolescents that was truly representative of the population of the region under study.

\section{Recruitment strategy}

Our social workers and medical officers convene initial introductory meetings with Gram panchayats (local governing body in the village), anganwadis (day-care centres), school/colleges and village women groups to:

- Educate them about our project objectives and its impact on the community.

- Counsel them about the health of adolescent girls and future health risks.

- Provide a space where adolescent girls can express themselves and raise issues that concern them.

- Identify village workers who could take a stand on social issues and influence opinion of the community.

- Elicit their support in baseline survey and data collection.

Establishing rapport and trust within the community and study participants is an important prerequisite before data collection. Our field workers attend local festivals, participate in local events like tree plantation drive, cleanliness drives. Social workers and medical officers conduct 
door-to-door survey to collect community specific data (demographic data, access to services like health, hygiene, education, etc). After preliminary screening to suit the selection criteria, a written informed consent from the parents and the assent from the adolescent girls are obtained for participation in the study. Parents are interviewed to obtain socioeconomic details and information not only about the status of their own health but also that of the girl. In addition, social mapping and socioeconomic survey of the village is conducted. We bring 8-10 adolescent girls for a 3-day residential camp at the institute's campus. Girls undergo various investigations and clinical examination. Our institute provides transport, accommodation and all the meals during their stay. The main purpose of bringing them to the hospital is the availability of the technical resources needed for various investigations and to ensure an 8 hour fasting stage before the blood, urine, and saliva samples are drawn in the morning. Parents are invited to the hospital on the last day of the camp for blood collection (random blood sample) and anthropometry.

All the study participants undergo awareness sessions and health education. Importance of this project and its benefits to the society are explained to the participants and their parents.

Subjects are screened with the help of a one-page questionnaire to determine their eligibility.

\section{Inclusion criteria}

1. Age $\geq 16$ years and $\leq 18$ years.

2. Adolescent girl and her parents must be native of Konkan and the girl must be living with her parents.

3. Be a biological child of her parents.

4. No history of any major illness (eg, heart, kidney, liver disease, cancer and psychiatric disorders) or a history of major surgery or organ transplant.

5. No history of mental, intellectual and physical disability.

6. No history of genetic or hereditary diseases (eg, Down's syndrome, haemolytic anaemia, etc).

\section{Data collection at recruitment}

\section{Demographic data}

Social workers visit the household to collect demographic data and document standard of living index questionnaire comprising of housing type, utilities and household possessions. ${ }^{31}$

Comprehensive baseline information is collected including information on demographics, medical and reproductive histories, number of siblings/birth order among siblings, menstrual history, medication use, family history of major diseases (eg, cancer, diabetes etc) and education/occupation.

\section{Body composition}

Anthropometric measures such as height, weight, and circumferences (head, mid-upper arm, waist and hip) are measured using standardised protocols. Body composition is assessed using bioelectrical impedance using MC-780 analyser (TANITA, Japan).

Nutrition

Food habits and meal pattern are recorded using a 24-hour recall of food consumed a day before the residential camp and food frequency questionnaire. In addition, subjects are also given a food diary where they record the items, quantity consumed, and time of consumption, over a period of 1 month. We plan to repeat food diary protocol thrice a year comprising three distinct seasons (summer, monsoon and winter) as it will cover school vacations during summer holidays and festivals. Unique food items and recipes are identified and then quantified for their nutrient profile. ${ }^{32} 33$

\section{Physical activity assessment}

We are using Global Physical Activity Questionnaire designed by WHO. ${ }^{34}$ We are also obtaining a recall of physical activity performed 24 hours prior to the residential camp. Study subjects are given a physical activity diary where they record the activities done, time spent on the activity, and time of activity over a period of 1 month. We plan to repeat physical activity diary protocol thrice a year comprising of the three distinct seasons (summer, monsoon and winter). Unique physical activities will be identified.

\section{Cognition and psychological assessment}

Cognitive evaluation of the subjects is being done by a certified clinical psychologist using a modified Indian version of the Wechsler Intelligence Scale for Children-IV (for subjects $<16$ years and 11 months) and Wechsler Intelligence Scale for Adults (subjects $\geq 17$ years). ${ }^{35}$ It is a widely used standard test designed to measure intelligence and cognitive ability in adults and older adolescents. Behavioural screening and psychological health issues will be identified using the Youth Paediatric Symptoms Checklist questionnaire. ${ }^{36} 37$

\section{Cardiometabolic and other investigations}

Blood pressure and the pulse rate are measured using automated monitor (OMRON-India). Ultrasonography of abdomen is done using Philips HD 11 ultrasound scanner. Dental, gynaecological and ophthalmic examinations are also performed on the study subjects.

\section{Biospecimen collection and storage}

We collect about $40 \mathrm{~mL}$ of fasting blood from each participant in Ethylene Diamine Tetra-acetic Acid (EDTA) vacutainers. The samples are kept in a portable, insulated cool box with ice packs (to maintain their temperature at $0^{\circ} \mathrm{C}-4^{\circ} \mathrm{C}$ ) and immediately sent to the laboratory for registration and processing. After centrifuging, each blood sample is aliquoted into 20 cryovials and then stored in $-80^{\circ} \mathrm{C}$ freezers. In addition, $10 \mathrm{~mL}$ of fasting saliva sample and $10 \mathrm{~mL}$ of urine sample are taken. We also collect random blood, saliva and urine samples of both parents and store them into freezers. Subject's 
micronutrient status of vitamin $\mathrm{B}_{12}, \mathrm{~B}_{1}, \mathrm{~B}_{2}, \mathrm{~B}_{6}$, Vitamin $\mathrm{E}$, Vitamin D, ferritin, calcium, folate, homocysteine, trace elements (iron, selenium, manganese, zinc, etc), liver function, renal function and hormones will be measured using stored plasma/serum samples.

\section{Biorepository}

We have setup a biorepository of biospecimens to be used in the future for the identification of DNA-based molecular markers to study genetic aspects of health and diseases.

\section{Data management}

We have created a relational data base system using MS (Microsoft) Access. We have complex lists that contain various types of information (eg, address and contact, past history, parent's history, medical examinations, laboratory measurements, monthly food diary data and monthly physical activity diary data). Data are organised containing information about only one type of data. This helps to avoid large number of columns in one table and unnecessary scrolling while entering the data, thus minimising the chance of inaccurate data entry. We designed user friendly data entry form corresponding to each table. We have assigned a unique identifier to each adolescent girl to preserve the integrity of our data and avoid duplication. The participants contact information and identification-related data are retained in a location separate from that of their medically sensitive data. Our system also provides the quickest way to retrieve the data when we need to carry out a data search. We have safeguards such as range checks, skips/jumps/flags in the data entry programme to prohibit the entry of impossible values to ensure data quality. Data in MS Access can be easily exported to advanced statistical tools such as SPSS 25.0, STATA 11.1 and R for further analysis. Data are backed up on daily and weekly basis on the local server as well as the central server of the institute.

\section{Community engagement}

Whenever necessary, results of medical investigations are used for counselling adolescents and their parents. During the process of building a cohort, subjects of our study are educated about nutrition. The $\mathrm{DOHaD}$ concept, and its implications for their present health and during their future pregnancy as well as the health of the subsequent generations is presented. Health education of girls will empower them to take care of their nutritional needs. In addition the local population comprising of village stakeholders, government officials, school teachers and parents are provided health information as well. Community engagement is a vital part of any project of this nature and the benefits such as better outcome for all stakeholders are well documented. Recruitment began on 23 June 2019 and by January 2020, we have recruited 300 adolescents in our study. The participation rate was $72 \%$ of those invited to take part. The main reason for non participation was unwillingness of parents to send their eligible adolescent girl for two nights stay at the institute. Some major festivals in the region and school examinations schedules also affected the participation. Participation is expected to rise dramatically after the final school examinations are over in the month of March. So far participation by parents has been (57.7\%) for mothers and $(21.0 \%)$ for fathers.

\section{Patient and public involvement}

Our adolescent girls are not actual patients and they were not involved in study's design or conduct. The results are disseminated at various follow up meetings in the community. The results are are also discussed with the parents when they visit the research centre on the last day of the residential camp.

\section{Postrecruitment follow-up schedule}

After recruitment, we plan to systematically follow our subjects as well as parents for years to come. Follow-up schedule and parameters to be measured are elaborated in figure 2. Adolescents will be followed up annually before and after marriage till they get pregnant. Mother and the fetus will be followed up antenatally as well postnatally. For each stage (except the recruitment stage) of the project, measurements in earlier stages will be treated as exposure. The adult NCD and diabetes risks will be determined by combinations of exposures in adolescence, preconception, antenatal period and postnatal period.

\section{Cohort maintenance strategy}

Our team of social workers is in constant touch with the families. They participate in local village fairs, festivals and community activities like cleanliness drives and tree plantation drives. All the adolescents have been given project identity cards. We have created adolescent groups in each village using digital communication programmes like Whatsapp so that any event such as illness, hospital admission, marriage, migration and death can be reported promptly to our centre. Each adolescent girl is contacted and greeted on her birthday and thanked on behalf of the entire team for her participation in our study. By keeping in touch with them, we expect to develop a rapport which will be very useful in maintaining long-term follow-up. We expect the retention rate of $100 \%$ till our subjects finish final year in the college or get married. After graduating from the college girls might migrate to other places for job, higher education or get married and migrate to husbands place within or outside the study area. This will certainly affect their subsequent participation in the later stages of the cohort but we are already in a process to develop a digital tracking system to handle migrations. Though some subjects might migrate to faraway places outside Konkan area, they can still be followed up when they visit their native places for some local festivals where their attendance is compulsory and is a social norm. In India there is a universal practice among pregnant women to migrate to mothers home for delivery in the seventh month of pregnancy. This will help in collection 


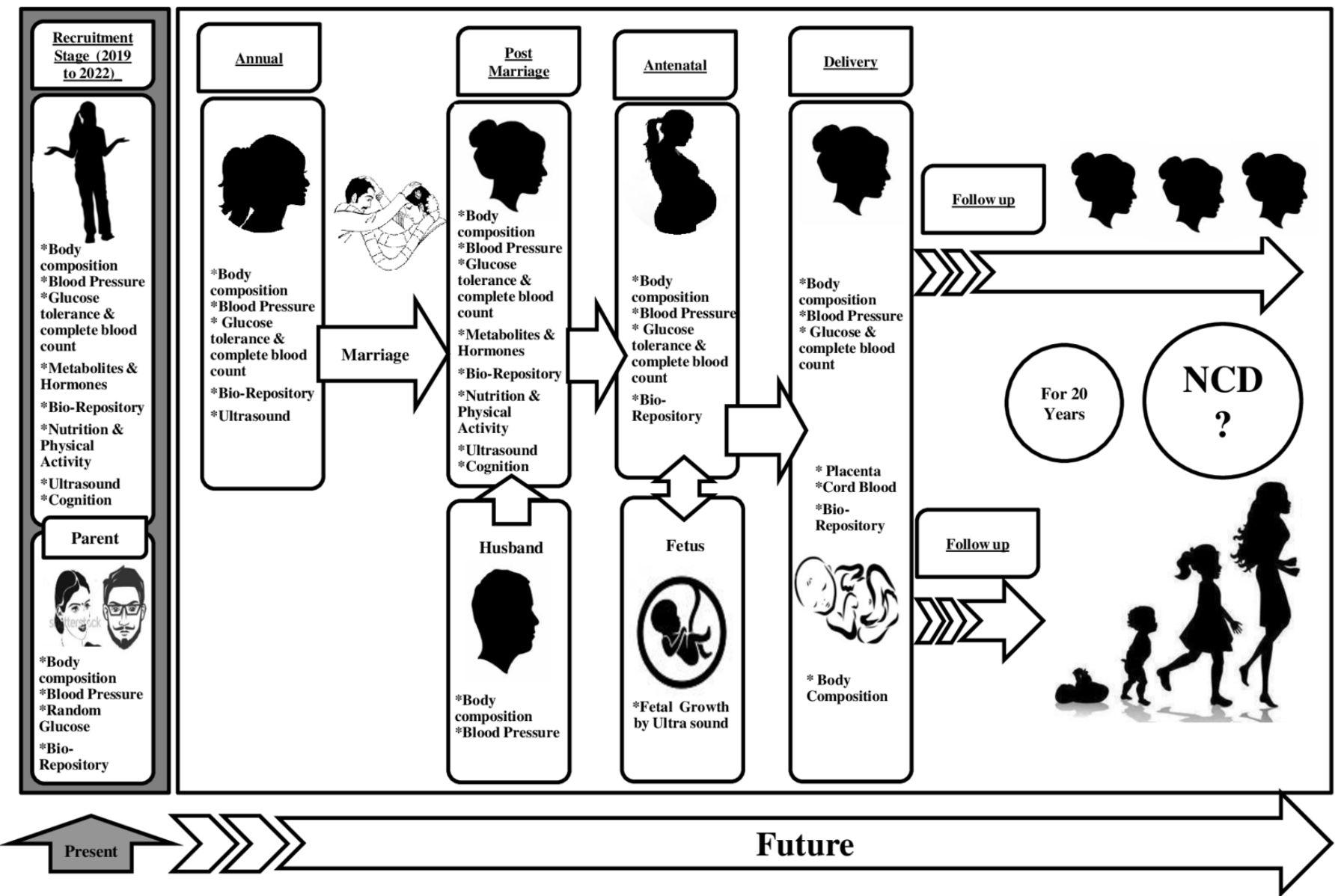

Figure 2 DERVAN cohort follow-up schedule (exposures at different stages). DERVAN, aDolescent and prEconception health peRspective of Adult Non-communicable diseases.

of antenatal measurements. Overall we expect a retention rate of $90 \%$. High retention rates have been observed in the two well-known prospective birth cohort studies from India which are now more than 20 years old. PMNS ${ }^{38}$ reports the retention rate of $90 \%$ while the Parthenon cohort reports that of around $85 \%-86 \% .^{39}$

\section{Generalisability of findings}

The issue of generalisability of the findings from our study is bound to be raised in future. The findings from $\mathrm{DOHaD}$ research in India are variable. ${ }^{25}$ Our adolescent girls and their parents are native of Konkan and live together as a family thus sharing the same environment. This is true at least until marriage. This may not be the situation in urban India where adolescent staying away from parents for education or jobs is becoming a norm and thus they get exposed to a very different environment. In addition, we would also like to emphasise that adolescent girls in our cohort are not sick; they are active and healthy girls, similar to those living in the villages throughout India. There is increasing urbanisation in India, however, $75 \%$ of India's population still lives in similar rural villages. We will put our findings in the context of the Konkan region. This project will help in designing, formulating and presenting region specific policies on national and international platform.

\section{Statistical methods}

Though body composition, diet are the main exposures and NCD risk factors (blood pressure, glucose, insulin and insulin resistance) are the main outcomes, there are many other variables which are measured. Epidemiological specifics of these variables are summarised in an online supplementary table. We have also summarised these variables using Directed Acyclic Graph in figure 3 which links the research hypothesis and the variables measured.

At baseline (stage 1), all data collected will be crosssectional in nature. Age, education of the girl, education of parents, socioeconomic status will be the confounders. Every variable will be tested for normality. Comparisons between the groups will be done by independent sample t-test for continuous variables and by $\chi^{2}$ test for categorical variables. Associations between exposures and outcomes will be analysed by regression models. As the cohort matures many variables especially the body composition and the markers for NCDs (blood pressure, glucose, insulin, insulin resistance) will acquire longitudinal form and become repeated measurement data. There are wellestablished methods (random-effect models, mixed-effect models, generalised estimating equations) to analyse such data which take into account correlations of within 


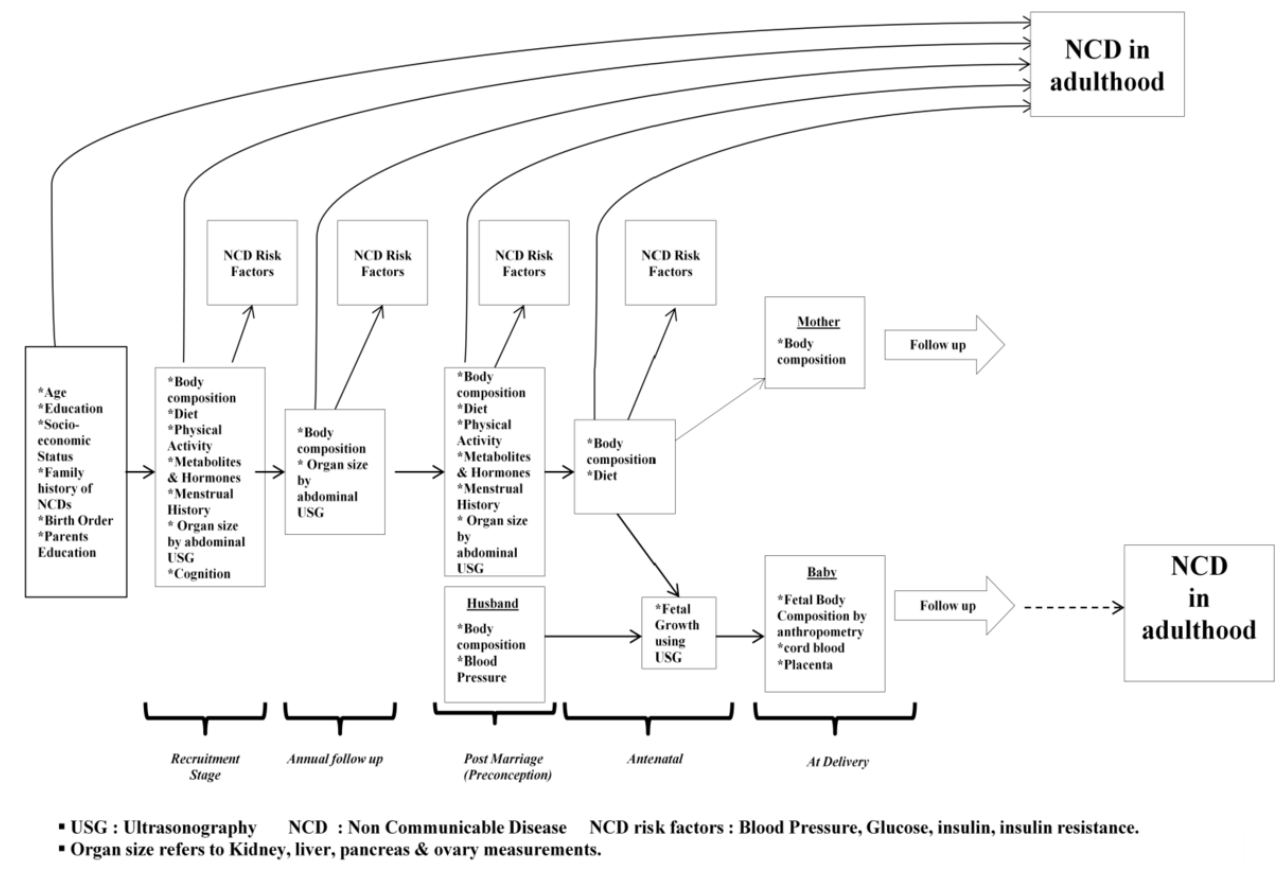

Figure 3 Direct acyclic graph (DAG) for DERVAN cohort. DERVAN, aDolescent and prEconception health peRspectiVe of Adult Non-communicable diseases.

subject measurements. Recently, conditional approach has also been suggested ${ }^{4041}$ to examine the association between later outcomes (NCDs, diabetes) and prior growth where adjustments are made for current and prior measurements. Longitudinal study of such a magnitude will have issues of attrition leading to missing data. Many data imputation methods have been suggested ${ }^{42}$ though commonly used imputation technique uses multiple regression model using the variables which are significantly associated at prior times. We will be using SPSS and STATA statistical packages for the analysis.

\section{ETHICS AND DISSEMINATION}

Institutional Ethic Committee (IEC) of BKL Walawalkar Hospital \& Rural Medical College has granted us the permission to carry out the study. IEC is registered with the Government of India. The registration code is EC/755/ INST/MH/2015/RR-18. Appropriate written informed consent and assent are obtained from the parents and the adolescent girls, respectively. A fresh consent will be obtained from adolescents as soon as they become 18 years old which is India's legal age of consent. Though this is not a clinical trial as per say, our study was also registered on Clinical Trial registry of India (CTRI) in April 2019, the reference code is CTRI/2019/04/018453. Reports will be annually submitted to Rajiv Gandhi science and technology Commission, a government body funding the study. Interim results will be presented at national and international conferences as well as to the scientific advisory committee of our institute which is composed of eminent scientists from India. We plan to publish study findings in international peer-reviewed journals and also disseminate them to local and national stakeholders as well as to the community.

\section{Author affiliations}

${ }^{1}$ Department of Medicine, BKL Walawalkar Hospital \& Rural Medical College, Sawarde, Maharashtra, India

${ }^{2}$ Department of Radiology, BKL Walawalkar Hospital \& Rural Medical College, Sawarde, Maharashtra, India

${ }^{3}$ Centre for Adolescent Health and Nutrition, BKL Walawalkar Hospital \& Rural Medical College, Sawarde, India

${ }^{4}$ Department of Biochemistry, BKL Walawalkar Hospital \& Rural Medical College,

Sawarde, Maharashtra, India

${ }^{5}$ Department of Pathology, BKL walawalkar Hospital \& Rural Medical College, Sawarde, Maharashtra, India

${ }^{6}$ Department of Obstetrics and Gynaecology, BKL walawalkar Hospital \& Rural medical College, Sawarde, Maharashtra, India

Acknowledgements We would like to thank all the government officials at the village level for giving us all the necessary help and also the permission to carry out the field level activities. We also thank the parents of the adolescent girls for giving us the consent to enrol their adolescent child. We would like to extend special thanks to our cohort team members without whom the study would not have progressed. The team members are Asmita Jadhav, Akshata Shembekar, Rohini Shinde, Siddhi Tandale, Menaka Bhosle, Pralobhana Deorukhkar, Sajeli Ghag, Omkar Dervankar, Dnyaneshwar Jadhav, Ajit Nandoskar, Sagar Chavan, Shravani Rokade, Rutuja Mohire, Pallavi Bhat. We would like to extend our thanks to Sanjiv Patankar, educator and advisor, the Department of Surgery, BKL Walawalkar Hospital for the final editing of the manuscript.

Contributors SP, CJ and RB wrote the manuscript. NP provided support for radiological measurements and $A Y, A N$ advised on laboratory measurements. UB and RM designed nutrition and physical activity measurement protocols. VD and BW helped us in the interpretation of pathology measurements. KJ carried out physical and gynaecological examination of adolescent girls.

Funding Rajiv Gandhi Science and Technology Commission, Government of Maharashtra, India, funds the study. Funding reference is https://rgstc.maharashtra. gov.in/sanctioned-projects. Grant Award sanction reference is RGSTC/File-2018/ DPP-195/CR-38. 
Map disclaimer The depiction of boundaries on this map does not imply the expression of any opinion whatsoever on the part of BMJ (or any member of its group) concerning the legal status of any country, territory, jurisdiction or area or of its authorities. This map is provided without any warranty of any kind, either express or implied.

Competing interests None declared.

Patient consent for publication Parental/guardian consent obtained.

Ethics approval Name- Ethics Committee of BKL Walawalkar Rural medical College \& Hospital ID: EC/755/INST/MH/2015/RR-18 provided by Government of India.

Provenance and peer review Not commissioned; externally peer reviewed.

Open access This is an open access article distributed in accordance with the Creative Commons Attribution Non Commercial (CC BY-NC 4.0) license, which permits others to distribute, remix, adapt, build upon this work non-commercially, and license their derivative works on different terms, provided the original work is properly cited, appropriate credit is given, any changes made indicated, and the use is non-commercial. See: http://creativecommons.org/licenses/by-nc/4.0/.

ORCID iD

Suvarna Patil http://orcid.org/0000-0002-9564-986X

\section{REFERENCES}

1 Barker DJ. Fetal origins of coronary heart disease. BMJ 1995;311:171-4.

2 Arokiasamy P. India's escalating burden of non-communicable diseases. Lancet Glob Health 2018;6:e1262-3.

3 IDF diabetes atlas 9th edition, 2019. Available: https://www. diabetesatlas.org/en/ [Accessed 21 Nov 2019].

4 Wild S, Roglic G, Green A, et al. Global prevalence of diabetes: estimates for the year 2000 and projections for 2030. Diabetes Care 2004;27:1047-53.

5 Yajnik CS. The insulin resistance epidemic in India: fetal origins, later lifestyle, or both? Nutr Rev 2001;59:1-9.

6 Keenan K, Hipwell AE, Class QA, et al. Extending the developmental origins of disease model: impact of preconception stress exposure on offspring neurodevelopment. Dev Psychobiol 2018;60:753-64.

7 Viner RM, Ross D, Hardy R, et al. Life course epidemiology: recognising the importance of adolescence. J Epidemiol Community Health 2015;69:719-20.

8 Blakemore S-J, Mills KL. Is adolescence a sensitive period for sociocultural processing? Annu Rev Psychol 2014;65:187-207.

9 Barker DJ, Gluckman PD, Godfrey KM, et al. Fetal nutrition and cardiovascular disease in adult life. Lancet 1993;341:938-41.

10 Warner MJ, Ozanne SE. Mechanisms involved in the developmental programming of adulthood disease. Biochem J 2010;427:333-47.

11 Dabelea D, Pettitt DJ. Intrauterine diabetic environment confers risks for type 2 diabetes mellitus and obesity in the offspring, in addition to genetic susceptibility. J Pediatr Endocrinol Metab 2001;14:1085-91.

12 Krishnaveni GV, Veena SR, Hill JC, et al. Intrauterine exposure to maternal diabetes is associated with higher adiposity and insulin resistance and clustering of cardiovascular risk markers in Indian children. Diabetes Care 2010;33:402-4.

13 Kshatriya GK, Acharya SK. Gender disparities in the prevalence of undernutrition and the higher risk among the young women of Indian tribes. PLoS One 2016;11:e0158308.

14 Sarin AR. Gender apartheid and its impact on Indian women's reproductive health. Indian J Matern Child Health 1992;3:33-5.

15 Sen A, Kanani SJ. Deleterious functional impact of anemia on young adolescent school girls. Indian Pediatr 2006;43:219-26.

16 Blencowe $\mathrm{H}$, Cousens S, Oestergaard MZ, et al. National, regional, and worldwide estimates of preterm birth rates in the year 2010 with time trends since 1990 for selected countries: a systematic analysis and implications. Lancet 2012;379:2162-72.

17 United Nations Inter-agency Group for Child Mortality Estimation (UN IGME). 'Levels \& Trends in Child Mortality: Report 2017, Estimates Developed by the UN Inter-agency Group for Child Mortality Estimation', United Nations Children's Fund, New York, 2017. Available: https://reliefweb.int/sites/reliefweb.int/files/resources/ Child_Mortality_Report_2017.pdf [Accessed 21 Nov 2019].

18 Tuyet Mai Tthi, Kim Hung Nthi, Kawakami M, et al. Macronutrient intake and nutritional status of primary school-aged girls in rural and urban areas of South Vietnam. J Nutr Sci Vitaminol 2003;49:13-20.
19 Scrimshaw NS. Consequences of hunger for individuals and societies. Fed Proc 1986;45:2421-6.

20 Tak J, Wadhawan N. Assessment of dietary micronutrient deficiency among adolescent girls. assessment of dietary micronutrient deficiency among adolescent girls. Food science research journal 2016;7:340-4.

21 Laxmaiah A, Arlappa N, Balakrishna N, et al. Prevalence and determinants of micronutrient deficiencies among rural children of eight states in India. Ann Nutr Metab 2013;62:231-41.

22 Bhutta ZA, Das JK, Rizvi A, et al. Evidence-based interventions for improvement of maternal and child nutrition: what can be done and at what cost? Lancet 2013;382:452-77.

23 Barker M, Dombrowski SU, Colbourn T, et al. Intervention strategies to improve nutrition and health behaviours before conception. Lancet 2018;391:1853-64.

24 Popkin BM. Nutrition transition and the global diabetes epidemic. Curr Diab Rep 2015;15:64.

25 Krishnaveni GV, Yajnik CS. Developmental origins of diabetes-an Indian perspective. Eur J Clin Nutr 2017;71:865-9.

26 Patil SN, Wasnik V, Wadke R. Health problems amongst adolescent girls in rural areas of Ratnagiri district of Maharashtra, India. Journal of Clinical and Diagostic Research 2009;3:1784-90.

27 Pevekar KS, Patil SN, Chavan AJ. Psychsocial study of adolescent girls from rural Konkan region (Maharashtra). International journal for research in medical sciences 2015;3:2745-50.

28 Patil S, Joglekar C, Desai M, et al. Nutritional Status and Psychological Impairment in Rural Adolescent Girls: Pilot Data From "KOKAN" Region of Western India. Front Public Health 2018;6:160.

29 Anjana RM, Pradeepa R, Deepa M, et al. Prevalence of diabetes and prediabetes (impaired fasting glucose and/or impaired glucose tolerance) in urban and rural India: phase I results of the Indian Council of medical Research-INdia diabetes (ICMR-INDIAB) study. Diabetologia 2011;54:3022-7.

30 Lwanga, Stephen Kaggwa, Lemeshow, Stanley \& World Health Organization. Sample size determination in health studies : a practical manual / S. K. Lwanga and S. Lemeshow. World Health Organization, 1991. Available: https://apps.who.int/iris/handle/10665/ 40062 [Accessed 10 Feb 2018].

31 International Institute for Population sciences (IIPS) and Operations Research Centre (ORC) Macro. National family health survey (NFHS2), India, 1998-99. Maharashtra. Mumbai: IIPS, 2001. https://www. dhsprogram.com/pubs/pdf/FRIND2/FRIND2.pdf

32 Gopalan C, Sastri BR, Balasubramanian SC. Nutritive value of Indian foods. Hyderabad, India: National Institute of Nutrition, Indian Council of Medical Research, 2004: 2-58.

33 Longvah T, Ananthan R, Bhaskarachary K, et al. Indian food composition table. Hyderabad, India: National Institute of Nutrition, Indian Council of Medical Research, 2017: 2-58.

34 Global physical activity questionnaire analysis guide GPAQ analysis guide global physical activity questionnaire (GPAQ) analysis guide. Available: http://www.who.int/chp/steps/GPAQ/en/index.html [Accessed 21 Nov 2019].

35 Wechsler D. Manual for the Wechsler intelligence scale for children. 3rd ed. San Antonio, TX: Psychological Corporation, 1991.

36 Jellinek MS, Murphy JM, Little M, et al. Use of the pediatric symptom checklist to screen for psychosocial problems in pediatric primary care: a national feasibility study. Arch Pediatr Adolesc Med 1999;153:254-60.

37 Jellinek MS, Murphy JM, Robinson J, et al. Pediatric symptom checklist: screening school-age children for psychosocial dysfunction. J Pediatr 1988;112:201-9.

38 Kumaran K, Yajnik P, Lubree H, et al. The Pune rural intervention in young adolescents (PRIYA) study: design and methods of a randomised controlled trial. BMC Nutr 2017;3:41.

39 Krishnaveni GV, Veena SR, Hill JC, et al. Cohort profile: Mysore parthenon birth cohort. Int J Epidemiol 2015;44:28-36.

40 Adair LS, Fall CHD, Osmond C, et al. Associations of linear growth and relative weight gain during early life with adult health and human capital in countries of low and middle income: findings from five birth cohort studies. Lancet 2013;382:525-34.

41 Osmond C, Fall CHD. Conditional Growth Models: An Exposition and Some Extensions. Chapter 11 p275-300. In: Srinivasa Rao ASR, Pyne S, Rao CR, eds. Handbook of statistics 37; disease modelling and public health, part B. Amsterdam, Netherlands: North Holland/ Elsevier, 2017.

42 Twisk J, de Vente W. Attrition in longitudinal studies. How to deal with missing data. J Clin Epidemiol 2002;55:329-37. 